\title{
Effects of local conspecific abundance on seed set and seed predation, and control of Carpinus laxiflora (Betulaceae) population density
}

\author{
Takuro Katori* and Tohru Nakashizuka \\ Graduate School of Life Sciences, Tohoku University, Sendai, 980-8578, Japan
}

\begin{abstract}
In this study, the dependence of local conspecific abundance on seed set and predation was examined, and determinates of population density of the temperate tree species Carpinus laxiflora (Betulaceae) in Inagi city, Tokyo, Japan were identified. During a good seed year (2013), seeds were sampled from 27 individuals and categorized as Sound, Empty, Predated, Immature, Decayed, or Broken. Empty seeds were identified as those that failed to fertilize and predation rates were defined as the proportion of seeds that were affected by predators. The proportion of the seed set that was fertilized was significantly positively correlated with local abundance of conspecific trees, while the proportion of seeds that escaped predation was significantly negatively correlated with local abundance of conspecific trees. Thereby, the production of Sound seeds was highest at sites with moderate local conspecific abundance. Although this phenomenon was only observed in a few cases, it clearly showed optimal reproductive success under conditions of moderate density of conspecific reproductive adults, suggesting a mechanism that controls the population density of this species.
\end{abstract}

Key words: Carpinus laxiflora, Janzen-Connell model, population density, reproduction success, seed predation, seed set

\section{INTRODUCTION}

Mechanisms that determine the population densities of tree species in forest communities are central to investigations of forest ecology, and it is widely accepted that the Janzen-Connell model (Janzen 1970, Connell 1971) contributes to the maintenance of species diversity in plant communities (Gilbert 2002, Howe and Miriti 2004). It is the effect that seedling density is maximized at a certain distance from the tree, because dispersed seed density decreases as the distance from the mother tree increases, and the proportion of seeds escaping from specific mortality due to disease or predation increases as the distance from the tree increases. This mechanism has been investigated in numerous studies and although refuted in some (Burkey 1994, Hyatt et al. 2003), has been observed for many species in temperate and tropical forests (Clark and Clark 1984, Lambers et al. 2002, Petermann et al. 2008, Mangan et al. 2010, Shibata et al. 2010).

Although the Janzen-Connell model describes seed and seedling stages, species dominance during pre-seed dispersal stages is subject to additional mechanisms, including the contradictory density dependence of pollination and seed/embryo predation. Previous studies have shown that pollination efficiency is positively correlated with local conspecific density of reproductive individuals. Moreover, multiple insect-pollinated plants are subjected to a decreased attraction of pollinators following fragmentation or isolation of the population (Silander 1978, House 1993, Ghazoul et al. 1998, García and Chacoff 2007, http://dx.doi.org/10.5141/ecoenv.2015.004

(1) \$ This is an Open Access article distributed under the terms of the Creative Commons Attribution Non-Commercial Licens (http://creativecommons.org/licenses/by-nc/3.0/) which permits unrestricted non-commercial use, distribution, and reproduction in any medium, provided the original work is properly cited.
Received 24 November 2014, Accepted 17 December 2014

*Corresponding Author

E-mail: takuro904@gmail.com

Tel: +81-22-7956698 
Dauber et al. 2010). Pollen limitations were also reported for wind-pollinated plants (Knapp et al. 2001). However, high seed and embryo predation has been associated with high local conspecific density in a number of studies (Steffan-Dewenter et al. 2001, García and Chacoff 2007, De Crop et al. 2012).

A few studies have examined the dependence of local density on both pollination and seed/embryo predation (Silander 1978, Steffan-Dewenter et al. 2001, García and Chacoff 2007), and although Silander (1978) found a positive correlation between conspecific density and seed sets, no significant correlations were found between predation rates and density. Steffan-Dewenter et al. (2001) also reported a positive correlation between the number of flower-visiting bees and the population density of a plant, and reported a negative correlation between the proportions of flower heads that escaped predation and plant density. García and Chacoff (2007) similarly showed a positive correlation between seed set and tree cover density, but the proportion of seeds that escaped predation (by mice) was also positively correlated with cover density. Hence, predator satiation (Janzen 1971, Silvertown 1980) may influence the correlation between the proportion of seeds that escaped predation and conspecific density. Taken together, these studies suggest an instability in the relationships between predation and local plant density.

In the present study, we assessed the effects of conspecific density on the reproductive success of Carpinus laxiflora (Betulaceae), which usually shows a scattered distribution in mature forests. Thus, to investigate the mechanisms that control its dominance, we examined the following aspects: 1) correlations between seed set and conspecific density, 2) correlations between the proportion of seeds that escaped predation and conspecific density, and 3) whether there is the moderate conspecific density for reproductive success.

\section{MATERIALS AND METHODS}

\section{Materials}

Carpinus laxiflora (Betulaceae) inhabits temperate deciduous forests in Japan and Korea (Ito 1989) and is dominant in some secondary forests of dry-mesic sites, but seldom dominates in old-growth forests (Masaki et al. 1992, Abe et al. 1995). This species is a wind-pollinated monoecious tree and has male and female inflorescences. Reproduction is initiated when trees reach about $3 \mathrm{~cm}$ in diameter at breast height (DBH). Flowers develop during early
April in this area, and fruit ripens in September-October. Seeds develop to full size even in unfertilized female flowers, and most remain on inflorescences until the main season of dispersal by wind (Shibata 2006). The larvae of Curculio spp. (Curculionidae) are known to be dominant seed predators of $C$. laxiflora (Shibata et al. 2002).

\section{Study site}

This study was performed in the broad-leaved deciduous secondary forests of Inagi City, Tokyo, Japan. The study area was about $3.8 \mathrm{~km}^{2}$ and was located at $35^{\circ} 38^{\prime}$ $\mathrm{N}, 139^{\circ} 30^{\prime} \mathrm{E}$. The mean annual temperatures of the nearest automated meteorological data acquisition system (AMeDAS) station, which was about $4 \mathrm{~km}$ away from the study site and had a similar elevation, was $15.0^{\circ} \mathrm{C}$, and the monthly maximum and minimum temperatures of $26.5^{\circ} \mathrm{C}$ and $4.2^{\circ} \mathrm{C}$ occurred in August and January, respectively. The mean annual precipitation is $1,529.7 \mathrm{~mm}$ (Japan Meteorological Agency 1981-2010). The original vegetation before human disturbance was likely broadleaf evergreen forest and was dominated by trees belonging to the subgenus Cyclobalanopsis, the genus Castanopsis, and Lauraceae (Nakanishi et al. 1983). The forests of the study site were converted to coppice forests several hundred years ago, and were typical of those in lowland and hill areas of central Japan. Until the 1970s, these forests were repeatedly cleared in 10-20 year cycles for firewood and charcoal production, and although most have been left with little management since (Iida and Nakashizuka 1995), they have been gradually fragmented by residential developments. The largest forest fragment of the study site is about $1.2 \mathrm{~km}^{2}$, and most are smaller than $1 \mathrm{~km}^{2}$. The studied forests are dominated by Quercus serrata (Fagaceae), and subordinate species include Q. acutissima, $C$. laxiflora and Cerasus jamasakura (Rosaceae) (Miyawaki 1986; Katori, personal observation).

\section{Selection of target individuals and survey of all reproductive individuals}

The 27 target individuals of C. laxiflora were $19-70 \mathrm{~cm}$ in girth at breast height (GBH), had flowers, and were not shaded by other trees. Target individuals were selected to cover a wide range of local conspecific tree densities, and locations of target individuals and neighboring reproductive individuals were recorded using a Garmin Global Positioning System (GPS) (Oregon 450 model; Garmin, Olathe, KS, USA). The error of Oregon 450 in the forest was within about $5 \mathrm{~m}$. The locations and GBHs of all repro- 
ductive individuals of the same species within up to $80 \mathrm{~m}$ from the target individuals (0-191 individuals within the range) were recorded from June to November 2013. The smallest reproductive individual was $8.3 \mathrm{~cm}$ in $\mathrm{GBH}$.

\section{Collection and classification of seeds}

Mature seeds of C. laxiflora were collected before dissemination from 2 to 3 sunny-sided branches of target trees at about a 3-m height using branch cutters between August 29 and September 7, 2013. Then, some inflorescences were randomly picked from each branch, and seeds were sampled from each inflorescence. At least 100 seeds (167 at most) were sampled from each target individual, and classified as Sound (seeds with Sound embryos), Predated (seeds with a hole made by insects), Empty (seeds of mature size but without embryos or signs of seed predation), Broken (seeds with a broken shape), Decayed (seeds with fungal decay), or Immature (seeds of Immature size without embryos). Empty seeds likely reflect the failure of fertilization of the seeds (Shibata et al. 2002), Broken seeds were seeds probably eaten by birds or mammals or terribly decayed, and Immature seeds may have been seeds affected by disease, insect predation, or various unknown morbidities before maturity. Broken, Decayed, and Immature may include both fertilized and unfertilized seeds. The discrimination of Broken and Decayed is vague.

\section{Analysis}

We analyzed the relationship between local conspecific abundance and seed set (we assumed it nearly equal to pollination rate, $P S$ ) or proportion of seeds that escaped from predation $(E S)$.

Four indices of local abundance of conspecific reproductive individuals were calculated from the population densities, distances from the target individuals, and basal areas. These included the following: 1) the sum of reproductive individuals within a particular distance from the target individual $(N L=n), 2)$ the sum of the tree density negatively weighted by the square of the distance from the target individual $\left.\left(N D=\sum^{n} d_{k}^{-2}\right), 3\right)$ the sum of the basal area of reproductive individuals within a particular distance from the target individual $\left(B A L=\sum^{n} B A_{k}\right)$, and 4$)$ the sum of the basal area negatively weighted by the square of the distance from the target individual $\left(B A D=\sum^{n} B A_{k} d_{k}^{-2}\right)$. In these calculations, $n$ is the number of reproductive individuals within a particular radius from each target individual, $d$ is the distance from the target individual to each reproductive individual, and $B A$ is the basal area of each of the reproductive individuals. The radii used for these indices were set at $20 \mathrm{~m}, 40 \mathrm{~m}, 60 \mathrm{~m}$, and $80 \mathrm{~m}$, respectively. The basal area of the target individual was used as a predictor variable, and may affect seed sets and predation of the corresponding individuals.

Subsequently, three indices for pollination and predation were applied as follows: 1) PS, (Sound + Predated)/ (Sound + Predated + Empty); 2) ES, Sound/(Sound + Predated); and 3) the proportion of Sound seeds (SS), Sound/ all seeds. Because Carpinus species develop seeds to full size in the absence of fertilization, most seeds remain on inflorescences until the main season of dispersal (Shibata 2006). Therefore, we assumed that Empty seeds were seeds that were not fertilized without effective pollination, and that Predated seeds as those Predated after they fertilized once. Because precise assessments of the causes of immaturity, breakage, and decay of seeds were not possible (see a section of "Collection and classification of seeds"), these seeds (Broken, Decayed, and Immature) were excluded from the calculations of $P S$ and $E S$.

The effects of local abundances of reproductive individuals ( $N L, N D, B A L$, and $B A D$ ) and the basal area of the target individual (predictor variables) on the indices of seed production success (PS and $E S$, response variables) were analyzed using a generalized linear mixed model (GLMM) with the glmmML package (Brostrom 2013) in R 3.1.0 (R Core Team 2014). Binomial error distributions and logit link functions were applied to the model. In these analyses, the units of replication for each seed and the identities of target individuals were used as a random variable. By GLMM, Akaike's Information Criterion (AIC) and $\mathrm{z}$-value were calculated. A large absolute value of $\mathrm{z}$ means that the estimated slope of a predictor variable is significantly different from zero, and the sign of $\mathrm{z}$ denotes the sign of the slope.

\section{RESULTS}

Almost all individuals over 9-cm GBH reproduced during the year of observation, and Sound seeds comprised $17 \%$ (range, 1-54\%) of all sampled seeds. In comparison with a previous study (Shibata et al. 2010), the year 2013 was one of the best out of recent seed years. The mean and range proportions of Predated, Empty, Immature, Broken, and Decayed seeds were $31 \%(0-63 \%), 27 \%(4-94 \%), 14 \%$ (0-43\%), 7\% (0-33\%), and 4\% (0-11\%), respectively.

The variables $P S$ and $E S$ were significantly correlated with most indices of local conspecific abundance, and the 
basal areas of target individuals did not have significant effects in most situations (Table 1). Moreover, stronger correlations with $N L$ or $B A L$ were generally stronger than that with $N D$ or $B A D$. PS was significantly and positively correlated with all indices of local conspecific abundance except for $B A D$ (Table 1), and the strongest correlation was found with $N L$ of a 80-m radius (Fig. 1a). Furthermore, $E S$ was significantly negatively correlated with all indices of local conspecific abundance except with that for $B A D$ of a 20-m radius (Table 1 ), and the strongest correlation was found with $N L$ of a 60 -m radius (Fig. 1b).

Thus, large conspecific abundance corresponded with increased Predated seed, whereas small local conspecific abundance was associated with increased Empty seeds. Consequently, SS showed a non-linear response to indices of local conspecific density. In particular, SS was highest at the middle and lowest ends of local conspecific abundance (Fig. 1c).

\section{DISCUSSION}

\section{The effect of local conspecific abundance on pollination efficiency}

Empty seeds comprised of $27 \%$ of the total number of seeds, suggesting that fertilization greatly influences seed production. Moreover, the observed positive correlation between local conspecific abundance and seed sets suggests pollen limitation (Fig. la). From the present data, the distance with the strongest correlation efficient was estimated as $80 \mathrm{~m}$. Among indices of local conspecific abundance, the number of reproductive individuals had the greatest effect on pollination efficiency, and that of basal areas of trees around the target individual and negatively weighted distances were less effective. The basal areas of individuals can be used to estimate the total amount of pollen produced by individual trees, and negative associations with the square of this distance may reflect distance effects. Although all of these indices can be used to make better estimations of seed set, the causes of differences between these indices remain unclear.

Pollen limitation during reproduction has been reported in multiple cases, and in agreement with Knapp et al. (2001), the data showed pollen limitation at $60-80 \mathrm{~m}$ in the wind-pollinated species Quercus douglasii. However, local abundance was measured within a radius of $80 \mathrm{~m}$ in both studies, and whether the most effective distance is larger remains unknown. Pollen limitation has also been reported for insect-pollinated plants (Silander 1978, House 1993, Ghazoul et al. 1998, García and Chacoff 2007, Dauber et al. 2010, Jakobsson and Ågren 2014). Among

Table 1. Effects of four indices of local densities of conspecific reproductive individuals (DCRI) and corresponding basal areas of target individuals on rates of pollination $(P S)$ and escape from predation (ES)

\begin{tabular}{|c|c|c|c|c|c|c|c|}
\hline & \multirow[b]{2}{*}{$\begin{array}{c}\text { Radius of } \\
\text { DCRI }\end{array}$} & \multicolumn{3}{|c|}{$P S$} & \multicolumn{3}{|c|}{$E S$} \\
\hline & & AIC & $\begin{array}{c}\text { z-value with } \\
\text { each DCRI }\end{array}$ & $\begin{array}{l}\text { z-value with basal } \\
\text { area of the target } \\
\text { individual }\end{array}$ & AIC & $\begin{array}{c}\text { z-value with } \\
\text { each DCRI }\end{array}$ & $\begin{array}{l}\text { z-value with basal } \\
\text { area of the target } \\
\text { individual }\end{array}$ \\
\hline \multirow[t]{4}{*}{$N L$} & $20 \mathrm{~m}$ & 2903.6 & $2.29^{*}$ & -1.21 & 1369.0 & $-4.59^{*+* t}$ & -1.61 \\
\hline & $40 \mathrm{~m}$ & 2901.3 & $2.86^{* *}$ & -0.85 & 1367.0 & $-5.04^{* * * *}$ & $-2.03^{*}$ \\
\hline & $60 \mathrm{~m}$ & 2896.5 & $3.86^{* * * *}$ & -0.47 & 1366.0 & $-5.25^{* * * *}$ & -2.15 \\
\hline & $80 \mathrm{~m}$ & 2892.6 & $4.61^{* * * *}$ & 0.25 & 1373.6 & $-3.69^{* * * *}$ & -1.6 \\
\hline \multirow[t]{4}{*}{$N D$} & $20 \mathrm{~m}$ & 2904.5 & $2.05^{*}$ & -1.25 & 1370.6 & $-4.21^{* * * *}$ & -1.51 \\
\hline & $40 \mathrm{~m}$ & 2904.0 & $2.2^{*}$ & -1.14 & 1369.5 & $-4.49^{* * * *}$ & -1.7 \\
\hline & $60 \mathrm{~m}$ & 2903.6 & $2.31^{*}$ & -1.08 & 1369.1 & $-4.57^{* * * *}$ & -1.75 \\
\hline & $80 \mathrm{~m}$ & 2903.4 & $2.36^{*}$ & -1.06 & 1369.2 & $-4.55^{* * * *}$ & -1.77 \\
\hline \multirow[t]{4}{*}{$B A L$} & $20 \mathrm{~m}$ & 2905.2 & 1.86 & -1.47 & 1376.8 & $-2.94^{* *}$ & -0.71 \\
\hline & $40 \mathrm{~m}$ & 2902.7 & $2.52^{*}$ & -0.94 & 1367.8 & $-4.86^{* * * *}$ & $-1.99^{*}$ \\
\hline & $60 \mathrm{~m}$ & 2897.9 & $3.56^{* * * *}$ & -0.57 & 1366.2 & $-5.17^{*+* t}$ & $-2.11^{*}$ \\
\hline & $80 \mathrm{~m}$ & 2893.5 & $4.44^{* * *}$ & 0.14 & 1371.3 & $-4.14^{* * *}$ & -1.83 \\
\hline \multirow[t]{4}{*}{$B A D$} & $20 \mathrm{~m}$ & 2906.9 & 1.13 & -1.96 & 1380.1 & $-2.11^{*}$ & -0.062 \\
\hline & $40 \mathrm{~m}$ & 2906.6 & 1.39 & -1.83 & 1378.9 & $-2.43^{*}$ & -0.27 \\
\hline & $60 \mathrm{~m}$ & 2906.4 & 1.47 & $\begin{array}{r}1.00 \\
-1.79\end{array}$ & 1378.7 & $-2.48^{*}$ & -0.3 \\
\hline & $80 \mathrm{~m}$ & 2906.3 & 1.5 & -1.77 & 1378.7 & $-2.48^{*}$ & -0.6 \\
\hline
\end{tabular}

${ }^{*} P<0.05,{ }^{* *} P<0.01,{ }^{* * * *} P<0.001 ; N L$, the sum of reproductive individuals within a particular distance from the target individual; $N D$, the sum of the tree density negatively weighted by the square of the distance from the target individual; $B A L$, the sum of the basal area of reproductive individuals within a particular distance from the target individual; $B A D$, the sum of the basal area negatively weighted by the square of the distance from the target individual; AIC, Akaike's Information Criterion; large absolute value of $z$ means that estimated slope of a predictor variable is significantly different from zero, and the sign of $z$ denotes sign of the slope; underlined numbers are the lowest AICs for PS or ES. 

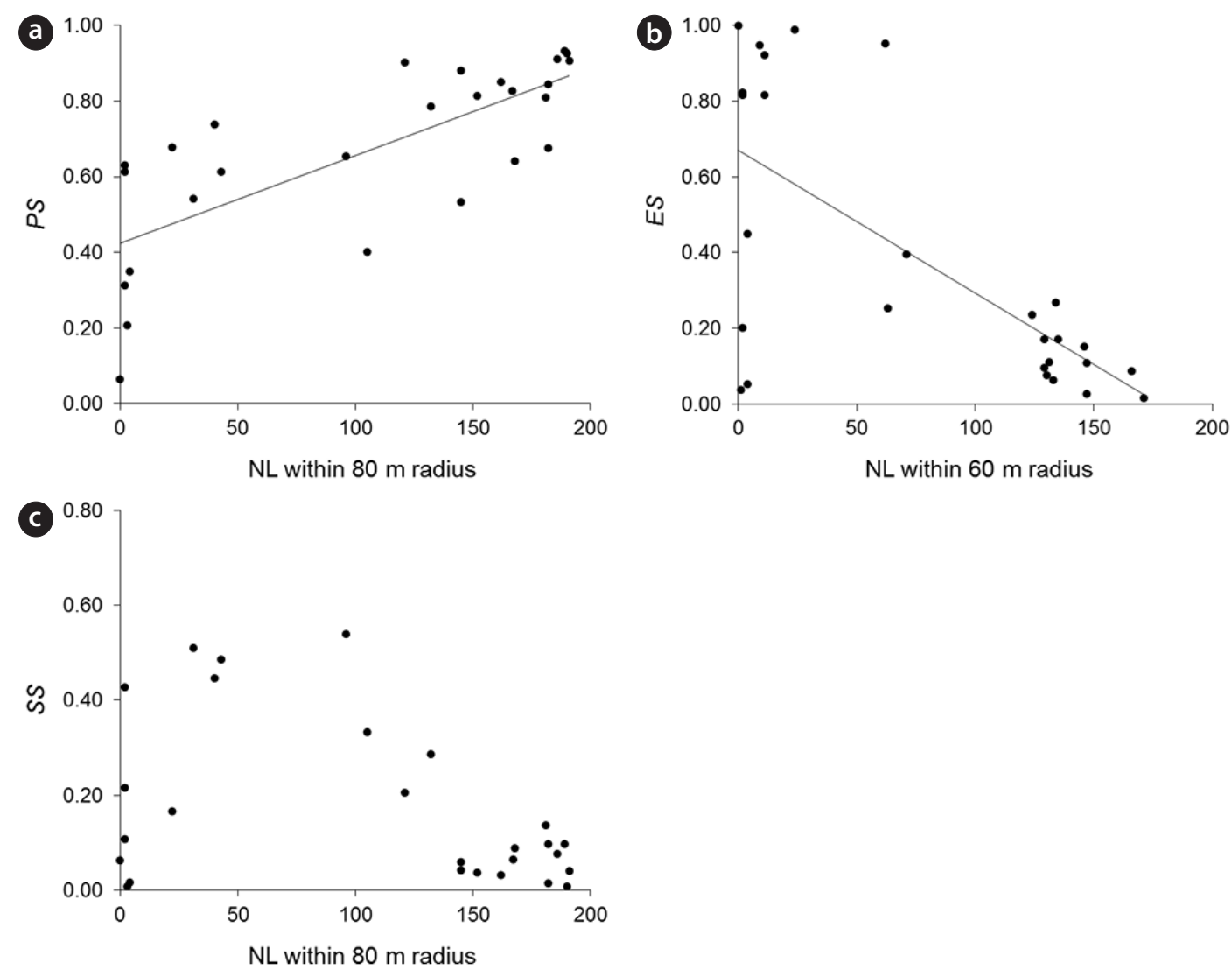

Fig. 1. Relationships between indices of local density of conspecific reproductive individuals and seed indices. (a) pollination rate (PS), (b) proportion of seeds that escaped from predation (ES), and (c) proportion of Sound seeds (SS).

these studies, only one (García and Chacoff 2007) used similar explanatory variables to those used in the present study, and showed that the strongest correlation occurred at $50-100 \mathrm{~m}$ from the target individual. However, these investigators also conceded that the most effective distance could be larger than $100 \mathrm{~m}$.

\section{The effect of local conspecific abundance on predation rates}

Predated seeds comprised of $31 \%$ of all seeds, suggesting that predation is an important factor for reproductive success. The proportion of seeds that escaped from predation was negatively correlated with the indices of local conspecific density (Fig. 1b), suggesting that population densities of C. laxiflora insect predators increased as the density of seed producing trees increased. However, the proportion of seeds that escaped from predation in areas of low conspecific density highly varied among sampled individuals. Because the proportion of seed predation may depend on the relative density of seeds and preda- tors, small variations in both seed and predator numbers may lead to large differences in the proportion of Predated seeds.

Annual fluctuations of seed production might have affected the present results, because during a good year of seed production, the proportion of seeds that escape predation tends to be high. This reflects the effects of predator satiation (Janzen 1971, Silvertown 1980) as confirmed for C. laxiflora (Shibata et al. 2002). Hence, because the present study was performed during a good seed year, further studies are required to assess these effects during a year of limited seed production. Nonetheless, good seed years may have a larger effect on the fitness of this species, because the proportions of Immature, Broken, and Decayed seeds are less, resulting in limited effects on reproductive success.

The proportions of seeds that escaped predation were most strongly affected by the density of reproductive individuals within a 60 -m radius. A previous study demonstrated that effective spatial scales of an insect-pollinated herb Centaurium erythraea for escape from predation 
were lower in more isolated populations (De Crop et al. 2012). Moreover, the predation rates of the insect-pollinated herb Centaurea jacea were more strongly positively correlated with the habitat density within a 250-m radius (Steffan-Dewenter et al. 2001) than those within a larger radius. In agreement with the present study, the predation rates of the insect pollinated shrub Crataegus monogyna were most strongly and negatively correlated with the tree cover in the range of 20-50 m (García and Chacoff 2007). However, no significant correlations were found between the predation rates and isolation of individuals of the insect-pollinated shrub Cassia biflora (Silander 1978). Hence, because the rate of seed predation may depend on the relative densities of seeds and predators, small variations in both seed and predator numbers may produce large differences in the proportions of Predated seeds, as observed in the areas of low conspecific reproductive density. Nonetheless, seed predation may also vary with annual fluctuations of seed production and predator populations.

\section{Optimal conspecific densities for the production of Sound seeds}

The best production of Sound C. laxiflora seeds was observed in areas of moderate conspecific adult trees density (Fig. 1c). Although few studies demonstrate the dependence of density on pollination efficiencies and seed predation (Silander 1978, Steffan-Dewenter et al. 2001, García and Chacoff 2007), Fujimori et al. (2006) suggested that the optimal densities of Kalopanax pictus may reflect pollination success and the presence of specific leaf diseases. Moreover, in a study on the insect-pollinated herb, C. jacea, the number of flower-visiting bees was positively correlated with the flowering plant densities, and in agreement with the present data, the proportion of flower heads that escaped predation was negatively correlated with density (Steffan-Dewenter et al. 2001). While optimal reproduction at moderate density was not reported in this study, Silander (1978) showed that the production of Sound seeds by the insect-pollinated shrub C. biflora was maximal in areas of moderate conspecific density as a hypothesis. However, no correlations between the predation rates and adult density were found, suggesting that reproduction may not have been optimal at moderate density (Silander 1978). In the study by García and Chacoff (2007), seed sets and the proportion of seeds that escaped predation (by mice) were positively correlated with tree cover density, again indicating that the production of Sound seeds was not optimal at areas of moderate density.
Taken together with previous studies, the present data indicate that although the maximum reproductive success in areas of moderate conspecific density occurs in only some cases, the associated mechanisms may be related to the control of population densities of plant communities.

\section{ACKNOWLEDGMENTS}

We thank Masaaki Takyu and Yukito Nakamura (Tokyo University of Agriculture) for their advice during the survey and writing of the manuscript. We acknowledge Michio Oguro (Tohoku University) for help with analyses. The authors would like to thank Enago (www.enago.jp) for the English language review. Our research has complied with the laws of Japan.

\section{LITERATURE CITED}

Abe S, Masaki T, Nakashizuka T. 1995. Factors influencing sapling composition in canopy gaps of a temperate deciduous forest. Vegetatio 120: 21-32.

Brostrom G. 2013. glmmML: Generalized linear models with clustering. R package version 1.0. http://CRAN.R-project.org/package=glmmML. Accessed 14 October 2014 .

Burkey TV. 1994. Tropical tree species diversity: a test of the Janzen-Connell model. Oecologia 97: 533-540.

Clark DA, Clark DB. 1984. Spacing dynamics of a tropical rain forest tree: evaluation of the Janzen-Connell model. Am Nat 124: 769-788.

Connell JH. 1971. On the role of natural enemies in preventing competitive exclusion in some marine animals and in rain forest trees. In: Dynamics of Populations (Den Boer PJ, Gradwell GR, eds). PUDOC, Wageningen, pp 298-312.

Dauber J, Biesmeijer JC, Gabriel D, Kunin WE, Lamborn E, Meyer B, Nielsen A, Potts SG, Roberts SPM, Sõber V, Settele J, Steffan-Dewenter I, Stout JC, Teder T, Tscheulin T, Vivarelli D, Petanidou T. 2010. Effects of patch size and density on flower visitation and seed set of wild plants: a pan-European approach. J Ecol 98: 188-196.

De Crop E, Brys R, Hoffmann M. 2012. The impact of habitat fragmentation on the interaction between Centaurium erythraea (Gentianaceae) and its specialized seed predator Stenoptilia zophodactylus (Pterophoridae, Lepidoptera). Ecol Res 27: 967-974.

Fujimori N, Samejima H, Kenta T, Ichie T, Shibata M, Iida S, Nakashizuka T. 2006. Reproductive success and dis- 
tance to conspecific adults in the sparsely distributed tree Kalopanax pictus. J Plant Res 119: 195-203.

García D, Chacoff NP. 2007. Scale-dependent effects of habitat fragmentation on hawthorn pollination, frugivory, and seed predation. Conserv Biol 21: 400-411.

Ghazoul J, Liston KA, Boyle TJB. 1998. Disturbance-induced density-dependent seed set in Shorea siamensis (Dipterocarpaceae), a tropical forest tree. J Ecol 86: 462-473.

Gilbert GS. 2002. Evolutionary ecology of plant diseases in natural ecosystems. Annu Rev Phytopathol 40: 13-43.

House SM. 1993. Pollination success in a population of dioecious rain forest trees. Oecologia 96: 555-561.

Howe H, Miriti MN. 2004. When seed dispersal matters. BioScience 54: 651-660.

Hyatt LA, Rosenberg MS, Howard TG, Bole G, Fang W, Anastasia J, Brown K, Grella R, Hinman K, Kurdziel JP, Gurevitch J. 2003. The distance dependence prediction of the Janzen-Connell hypothesis: a meta-analysis. Oikos 103: 590-602.

Iida S, Nakashizuka T. 1995. Forest fragmentation and its effect on species diversity in sub-urban coppice forests in Japan. For Ecol Manage 73: 197-210.

Ito K. 1989. Betulaceae. In: Wild Flowers of Japan, Woody Plants I (Satake Y, Hara H, Watari H, Tominari T, eds). Heibonsha, Tokyo, pp 52-65. (in Japanese)

Jakobsson A, Ågren J. 2014. Distance to semi-natural grassland influences seed production of insect-pollinated herbs. Oecologia 175: 199-208.

Janzen DH. 1970. Herbivores and the number of tree species in tropical forests. Am Nat 104: 501-528.

Janzen DH. 1971. Seed predation by animals. Annu Rev Ecol Syst 2: 465-492.

Japan Meteorological Agency. 1981-2010. The mean annual and maen monthly AMeDAS data in Huchu. http:// www.data.jma.go.jp/obd/stats/etrn/view/nml_amd_ ym.php?prec_no=44\&block_no $=1133 \&$ year $=\&$ month $=\&$ day=\&view=. Accessed 18 September 2014. (in Japanese)

Knapp EE, Goedde MA, Rice KJ. 2001. Pollen-limited reproduction in blue oak: implications for wind pollination in fragmented populations. Oecologia 128: 48-55.

Lambers JHR, Clark JS, Beckage B. 2002. Density-dependent mortality and the latitudinal gradient in species diver- sity. Nature 417: 732-735.

Mangan SA, Schnitzer SA, Herre EA, Mack KML, Valencia MC, Sanchez EI, Bever JD. 2010. Negative plant-soil feedback predicts tree-species relative abundance in a tropical forest. Nature 466: 752-755.

Masaki T, Suzuki W, Niiyama K, Iida S, Tanaka H, Nakashizuka T. 1992. Community structure of a species-rich temperate forest, Ogawa Forest Reserve, central Japan. Vegetatio 98: 97-111.

Miyawaki A. 1986. Vegetation of Japan: Kanto. Vol, 7. Shibundo, Tokyo. (in Japanese)

Nakanishi S, Ohba T, Takeda Y, Hattori T. 1983. Illustration of Vegetation in Japan, Vol. I, Forest Vegetation. Hoikusha, Osaka. (in Japanese)

Petermann JS, Fergus AJF, Turnbull LA, Schmid B. 2008. Janzen-Connell effects are widespread and strong enough to maintain diversity in grasslands. Ecology 89: 23992406.

R Core Team. 2014. R: A language and environment for statistical computing. R Foundation for Statistical Computing, Vienna, Austria.

Shibata M. 2006. Meanings of seed set synchronization in many species. In: Forest Ecology, with Long-term Perspectives (The Society for the Study of Species Biology, ed). Bun-ichi Sogo Shuppan Co., Tokyo, pp 39-57. (in Japanese)

Shibata M, Masaki T, Tanaka H, Niiyama K, Iida S, Abe S, Nakashizuka T. 2010. Effects of abiotic and biotic factors and stochasticity on tree regeneration in a temperate forest community. Ecoscience 17: 137-145.

Shibata M, Tanaka H, Iida S, Abe S, Masaki T, Niiyama K, Nakashizuka T. 2002. Synchronized annual seed production by 16 principal tree species in a temperate deciduous forest, Japan. Ecology 83: 1727-1742.

Silander JA Jr. 1978. Density-dependent control of reproductive success in Cassia biflora. Biotropica 10: 292-296.

Silvertown JW. 1980. The evolutionary ecology of mast seeding in trees. Biol J Linn Soc 14: 235-250.

Steffan-Dewenter I, Münzenberg U, Tscharntke T. 2001. Pollination, seed set and seed predation on a landscape scale. Proc R Soc Lond B 268: 1685-1690. 